\title{
El Museo de Cera. Fragmentación, Anacronismo, Fractalidad ${ }^{1}$
}

\author{
Dr. Juan D. Cid Hidalgo ${ }^{2}$ y Mag. Óscar Gutiérrez Muñoz ${ }^{3}$, \\ Universidad de Concepción, Chile \\ Recibido: 19 de marzo, 2016. \\ Aceptado: 15 de mayo, 2016.
}

\section{Resumen:}

El presente artículo analiza la novela El museo de cera del narrador chileno Jorge Edwards. En él se describe, a partir de categorías críticas específicas, la forma en que se tematiza el museo y las múltiples relaciones que se pueden establecer entre espacio plástico y espacio literario. El trabajo con lugares ficticios y con espacios de identificación histórica, apuntan al despliegue de una interzona desde donde se proyecta la crítica social, con la cual busca generar discursos de características duales: por una parte el montaje de una novela episódica y por otra la creación de una colección (galería o exposición), espacio museal con instantáneas acerca de la historia particular de la ciudad y del personaje central, actividades ambas propicias para descargar comentarios sociopolíticos, económicos y culturales sobre aquella comunidad "imaginada". De esta forma se nota una especie de sensibilidad museal en el texto, que ayuda a reconocer la decisiva importancia del acto de coleccionar, montar, disponer y "curar" archivos, entendiendo que esta actividad se concreta al trabajar con la memoria. En la novela de Edwards, el museo adopta las características de un dispositivo que ejerce fuerza en el acto de seleccionar, reunir, separar y articular aquellos objetos (obras) de acuerdo con una intencionalidad política.

\section{ABSTRACT:}

\section{EL MUSEO DE CERA. FRAGMENTATION, ANACHRONISM, FRACTALITY}

This paper analyzes the short story El museo de cera by the Chilean author Jorge Edwards. It describes, using specific criticism categories as point of departure, the way in which the museum is themed and the multiple relationships that can be constructed between the plastic space and the literary one. The use of fictitious places and spaces with historical identification, aim at the deployment of an interzone from which social criticism is projected, which pursues the generation of a twofold discourse: On one hand the set up of an episodic novel, and, on the other hand, the creation of a collection of (gallery or exibit), a museum-like space with instant photos of the particular history of the city and of the main character, both activities aimed at unloading socio-political, economic and cultural criticism. Thus, a museum sensibility is perceived in the text, which helps us to acknowledge the decisive importance of collecting, mounting, arranging and "curating" files which with the understanding that this activity becomes actual when working with memory. In Edwards' novel the museum adopts characteristics of a device that exerts force in the acts of selecting, gathering, separating and articulating such objects (works) based upon a nationalistic intention.

1 Este trabajo fue concebido en el contexto del proyecto FONDECYT № 11121221. Apuntes sobre la dimensión museal de la literatura latinoamericana o los museos de papel, cuyo investigador principal es el Dr. Juan D. Cid Hidalgo. En él se han rastreado las materializaciones narrativas del museo (museo de papel) en la novela latinoamericana para identificar, lo que hemos llamado, sensibilidad museal de la novela latinoamericana.

2 Juan D. Cid Hidalgo es Doctor en Literatura Latinoamericana, profesor asistente del Departamento de Español, de la Facultad de Humanidades y Arte de la Universidad de Concepción, Chile. Contacto: jdcid@udec.cl.

3 Óscar Gutiérrez Muñoz es Magíster en Literaturas Hispánicas de la Universidad de Concepción e investigador. Contacto: ogutierrez@udec.cl
Juan D. Cid Hidalgo y Óscar Gutiérrez Muñoz. El museo de cera. Fragmentación anacronismo, fractalidad. Revista Comunicación. Año 37, volumen 25, número 1, enero-junio, 2016. Instituto Tecnológico de Costa Rica. ISSN: 0379-3974 / e-ISSN1659-3820. 


\section{INTRODUCCIÓN: CURATORÍA4 DEL RELATO}

Con la aparición del museo en el horizonte de la modernidad también se configura su potencia simbólica y el rápido ascenso a la consagración como un dispositivo (Castilla, 2010) que selecciona, reúne, conserva, hospeda y sanciona aquello que culturalmente es valioso y que forma parte de lo que puede ser definido como patrimonio inmaterial. Castilla (2010) sostiene enérgicamente que "en sus colecciones se encuentran las evidencias materiales de todos los enunciados que componen el cuerpo de la cultura, sus indicios y sus marcas" (p. 17) con lo cual abre una discusión francamente apasionante que dice relación, ahora desde Foucault (2004), con que aquello resguardado y prestigiado como valioso es material primero y último de una construcción discursiva particular, parte de un proyecto mayor, en algunos casos ideológico, en otros político y en otros utópicos.

Pensar el museo desde la literatura nos permite, entonces, relativizar los criterios de autoridad de aquellas instituciones que se han instalado como organismos republicanos sostenedores de un proyecto de nación, como la gran institución del quehacer cultural (Lopes, 2010). Pero además nos facilita la apreciación de la categoría autor y narrador, desarrollando una labor curatorial de organización plástica o montaje, de selección de materiales y de intensificación de ciertas zonas de una obra. Como vemos, el trabajo literario con el museo abre otras perspectivas para pensar los dominios del arte y sus materializaciones narrativas: los museos de papel

La reflexión sobre este espacio de poder desde la novela nos ayuda a entenderlo como una estructura carcelaria que, por cierto, no trabaja con cuerpos a los cuales disciplinar, pero sí con productos culturales de orden simbólico e intelectual, en muchos casos peligrosos para la estabilidad de la sociedad.

$4 \quad$ Entendemos esta actividad especializada a cargo del curador como "una estructura de mediación entre el artista y el público a través de un discurso que implique y refleje el conocimiento tanto del artista como de la colección, la selección de ésta y el ordenamiento que mejor muestre al público la tesis propuesta, sin dejar de lado los objetivos y la imagen del lugar en el que se exhibe" (Nieto, 2014, p. 19). En Chile el uso extendido de la actividad de curador es denominado "curatoría", aun cuando tenemos plena conciencia de que en otras zonas de América se utiliza el término "curaduría". Para efectos de esta investigación emplearemos el vocablo tal como se usa entre los profesionales del arte en Chile.
Es en este contexto en el que se inscriben las siguientes páginas.

Jorge Edwards (1931 - ) publica El museo de cera en 1981, novela que se diferencia de sus antiguos trabajos al alejarse de la tradición realista y testimonial a la cual nos tenía acostumbrados, para escoger, esta vez, un registro más complejo, un espectro amplio que transita en los márgenes de procesos sociohistóricos, espacio desde el cual despliega una dimensión crítica en torno a aquellos movimientos sociales del pasado inmediato de cualquier país latinoamericano. La novela exhibe, una vez más, esa veta cronológica tan presente en la escritura del narrador chileno, siendo la historia del Marqués de Villa Rica (personaje principal de la obra) un trabajo donde se manifiestan las relaciones, tensiones, cercanías y distancias entre el presente y el pasado, entre lo real y lo ficticio, en el contexto de un relato país cifrado en la figura mayor del Marqués, un noble hacendado, con una historia personal sui generis y que el narrador focaliza a partir de su articulación con las distintas situaciones que lo rodean.

La historia pareciera centrarse en el vouyerismo del protagonista, quien desde su posición privilegiada puede vincularse de forma (in)directa con los actores sociales que lo circundan:

En los últimos tiempos he sentido la tentación de hacerme rojo. Solo para trastornar el orden de las cosas, que a veces me parece agobiador, sofocante, ¿comprende usted? y para que los tirillentos tengan un mendrugo de pan... Pero nadie me creería, ¿no le parece? (Edwards, 2000, p. 102).

Dicho espacio de observación se traslada también a la vida privada del Marqués, espacio donde le tocará presenciar una escena de adulterio por parte de su esposa, clave para el desarrollo de la acción.

El Marqués, con palabras insinuantes y rápidas vibraciones de las manos, describía los muslos albos de Gertrudis dibujados contra la negrura del piano de cola, duplicados en la caoba bruñida como en un espejo, y luego trataba de transmitir el sonido y el efecto de sus lamentaciones, de sus voluptuosos 
quejidos. "Nunca me lo habría imaginado" (Edwards, 2000, p. 37).

Este hecho, que pareciera ser el punto de inflexión para comenzar a narrar la historia de degradación social de una ficticia Villa Rica ${ }^{5}$, no es más que otro aliciente para configurar la imagen del Marqués como una construcción simbólica totalizante, pese a que la novela se inserta más bien en un modelo de escritura que ofrece una visión segmentada de la realidad. Esta modalidad textual inevitablemente, provocará un relato fragmentado en los niveles narrativo, histórico y semántico, junto con la imposibilidad de identificación de un narrador específi$\mathrm{co}$, una perspectiva histórica definida y una estructura narrativa única. La novela también nos invita a participar en un ambiguo pacto ficcional donde los márgenes históricos han perdido su rigidez. En este sentido, observamos construcciones como la siguiente:

El Marqués, con sus títulos, con su mansión principesca, con sus fabulosas colecciones y sus coches de cuatro caballos, e incluso con su prestancia física y su educación europea, sus erres de entonación ligeramente exótica, sus bromas Ilenas de alusiones oscuras, desentonaba en nuestro pequeño mundo" (2000, p. 11), o "Do you want a cup of tea?", insistió la Cocinera. - "Sí", dijo el correo de a caballo: "Con mucho gusto (2000, p. 139).

Estas descripciones de un aire marcadamente renacentista se ven contrapuestas a otras frases tales como "Habían dejado los sables en los rincones, y dos de ellos, por lo menos, advirtió el Marqués, llevaban enormes pistola ametralladoras, y walkie talkies de ingeniería japonesa, especiales para comunicarse entre puestos de mando" (2000, p. 53) o "La gendarmería hizo uso de sus armas de fuego en la plaza de la Reforma, a media cuadra de distancia

5 Villarrica es una ciudad y comuna de Chile, de la Provincia de Cautín en la IX Región de Araucanía. Integra junto a Gorbea, Cunco, Loncoche, Pucón, Curarrehue, y Toltén el Distrito Electoral $N^{\circ} 52$ y pertenece a la $15^{\mathrm{a}}$ Circunscripción Senatorial (Araucanía Sur). La ciudad de Villarrica, de 50.706 habitantes, se emplaza a $227 \mathrm{msnm}$, y a orillas del lago del mismo nombre. Esta ciudad es tomada como referencia, como un imaginario visual del sur de Chile, sin embargo, sus características y su historia particular no son tomadas en cuenta en la ficcionalización llevada a cabo por Edwards en El museo de cera. del Club, y hubo dos víctimas (...), los disturbios después amainaron. Los principales activistas, fueron perseguidos con helicópteros y perros de caza" (2000, p. 57), caracterizaciones de revueltas identificables con procesos bélicos e instancias de guerrilla propias del siglo XX y tan reconocibles como sistemáticos en la historia de los países latinoamericanos.

En principio, estas materializaciones narrativas nos acercan a lo que podríamos denominar anacronismo. Siguiendo a Fernández (2004) puede entenderse el concepto como "una incongruencia temporal que consiste en insertar en un período histórico elementos materiales o categorías culturales que pertenecen a otro, anterior o posterior" (Fernández, 2004, p. 250). Para la autora, dichas modalidades discursivas pueden ser de carácter material o arqueológico -y por lo tanto, van adornando el "espacio diegético con todo un conjunto de elementos que signifiquen ese pasado, que lo connoten que funcionen como imágenes o iconos del pasado real" (Fernández, 2004, p. 250)-; de carácter cultural y psicológico, que apunta a los espacios de representación de los personajes, ya sean " históricos o inventados y que actúan en la diégesis ficcional, a sus conductas, actitudes y reflexiones, a la repercusión en su vida privada e íntima de los acontecimientos públicos, a su manera de interpretarlos, a su integración del espacio diegético" (Fernández, 2004, p. 252); y de carácter verbal, que apunta a la utilización de modales estilísticos del habla y de los sociolectos en el espacio narrativo.

En El museo de cera nos encontramos, en menor o mayor medida, con estos recursos narrativos; sin embargo, pareciera ser que el autor no busca impactarnos con el quiebre histórico del espacio narrativo. La disposición de lugares ficticios que remiten a lugares reales, y espacios de identificación histórica que transitan en delgadas líneas de ficcionalidad, apuntan a desarrollar un espacio crítico en el cual pueda desplegar sus opiniones, su mirada, su crítica. Edwards construye, así, una "novela histórica en un sentido actual, no programática, no totalizante, sin pretensiones de ser un gran relato abarcador, exhaustivo, desplegado desde una concepción segura de la historia" (Schopf, 2004, p. 90), por eso se permite estos quiebres temporales, esta 


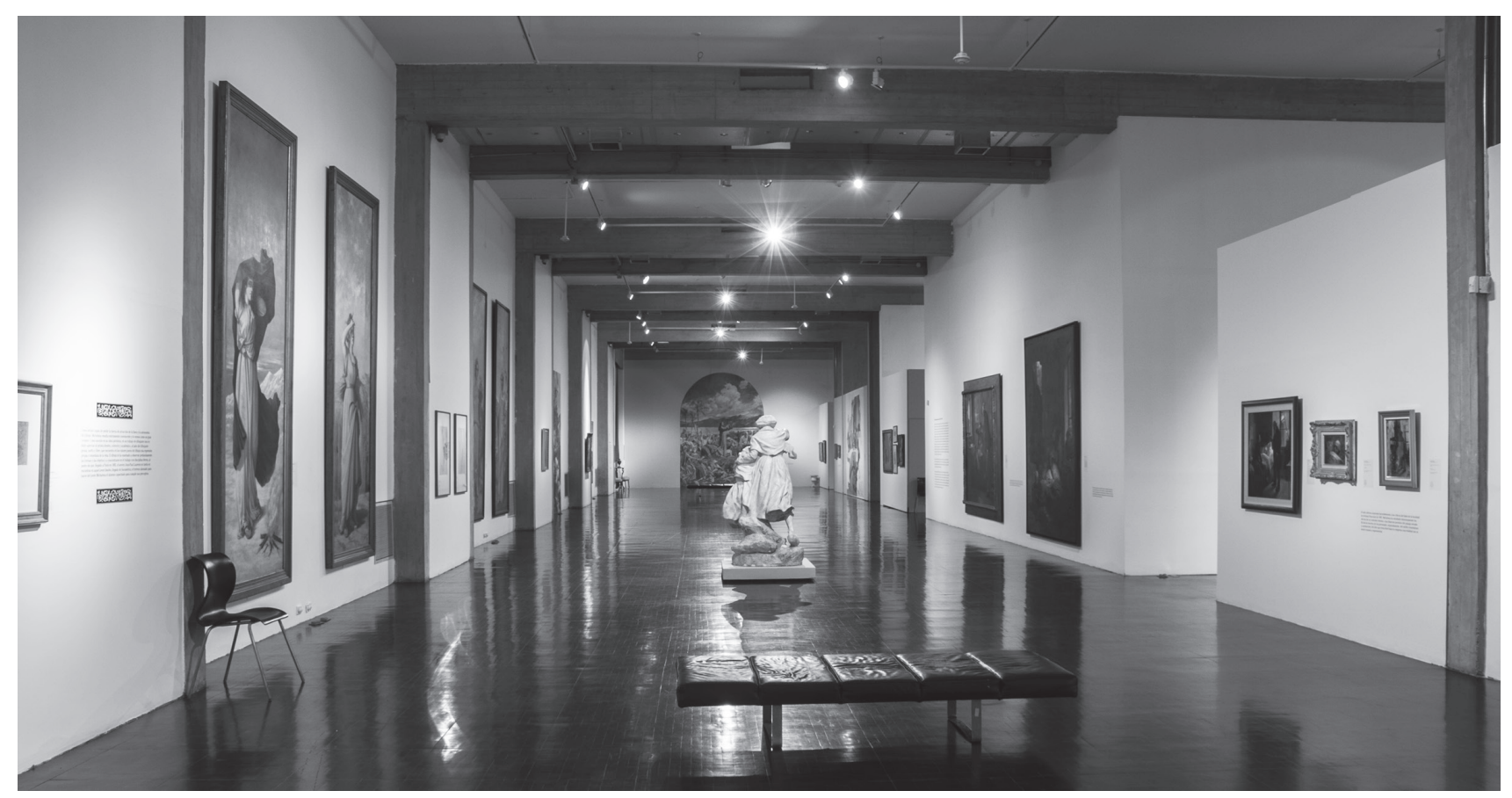

fragmentación en la mimesis del espacio narrativo y la experimentación con el montaje de la novela, actividad curatorial ${ }^{6}$ que comparte con el Marqués, conocedor del mundo del arte y de su tratamiento. Dicha particularidad genera una escritura espontánea a partir de una característica discursiva distinta a lo que comúnmente había desarrollado la generación narrativa, dentro de la cual se suele incorporar la escritura del chileno: la generación del 507 .

Schulz-Cruz (1992) describe en términos generales el ejercicio narrativo del novelista:

6 Ejercicio de manejo, conocimiento y distribución (montaje) de archivos fundamentalmente de naturaleza plástica. En el contexto de la presente investigación, esta práctica se transforma en una praxis de la memoria, en una actividad provocadora de constitución memorial. Jacques Derrida en "El cine y sus fantasmas" (2001) anota que "El archivo es una violenta iniciativa de autoridad, de poder, es una toma de poder para el porvenir, preocupa el porvenir; confisca el pasado, el presente y el porvenir. Sabemos muy bien que no hay archivos inocentes" (web). "La archivación produce, tanto como registra, el acontecimiento" (24) acotará el mismo Derrida, ahora en Mal de archivo (1997). Las colecciones, entonces, exponen, además de los objetos eminentes, representativos y cuya dignidad amerite su vigencia en el futuro, la violencia en la conformación del corpus.

7 Sobre la Generación del 50 existe una bibliografía abundante de la cual recomendamos algunos títulos. Ahumada (1999), Godoy (1991 y 1998), Espinoza (1958), Giaconi (1959), Goic (1960), Lafourcade (1959) y Promis (1993). Por último, recomendamos el artículo "Generación Literaria de 1950" anclado en el sitio web http://www.memoriachilena.cl/602/w3-article-3434.html.
Es obvio que los textos de Edwards no se encasillan en la escritura testimonial, de emergencia y circunstancial, sería injusto, sin embargo, pedirle a Edwards un texto con obreros y campesinos. Él ha venido escribiendo desde el territorio de una clase que conoce bien. Además, en su narrativa se pone en evidencia que la visión de la burguesía se vuelve insuficiente para explicar la historia de Chile. Sus novelas se insertan en la red de escritura que ofrece una visión fraccionada de la realidad, evitando el intento totalizador —situación ya abandonada en toda Latinoamérica después del "Boom" — dado que no se puede dar cuenta de todo debido a la ausencia de la otra verdad, de la otra historia que se podría haber contado y de la imposibilidad de acceder al otro (p. 248).

Dicha propuesta nos lleva a la pregunta: ¿cómo exponer la gran cantidad de discursos que construyen el espacio memorial de una nación? En el desarrollo de la novela, Edwards exhibe los procesos constitutivos de la historia contemporánea de una ciudad ficticia, Villa Rica, la cual perfectamente podría ser una ciudad de cualquier país de América Latina, pues todas las naciones que la componen 
han sufrido una historia de violencia protagonizada por regímenes tanto de izquierda como de derecha. Mediante la figura central del Marqués se presenta, se exhibe, se monta, se curatoría la historia de una ciudad en proceso de desaparición. Así, la fragmentación histórico temporal, unida al carácter extravagante de la ciudad, van configurando al Marqués como depositario de una cualidad de las construcciones culturales de la contemporaneidad, la fractalidad (Baudrillard, 1990), herramienta narrativa a través de la cual se edifica un espacio crítico, en la medida en que se vale de su cualidad facilitadora de la velocidad de transición entre los espacios de acción. Ello queda manifiesto en las particularidades que la novela presenta en su construcción temporal, y que atribuirían un mayor espesor a la ya tumultuosa figura del terrateniente. De esta forma, tanto la novela como el narrador, experimentan cambios gracias a diversos mecanismos fractales (estatización temporal, polivalencia de imágenes, experimentación de velocidad en los cuerpos, p.e.), con los cuales pretenden abarcar todas las modalidades de conocimiento y todas las estructuras funcionales posibles que entran en contacto con su espacio de acción. Baudrillard (1990) señala:

La trascendencia ha estallado en mil fragmentos que son como las esquirlas de un espejo donde todavía vemos reflejarse furtivamente nuestra imagen antes de desaparecer. Como fragmentos de un holograma, cada esquirla contiene el universo entero. La característica del objeto fractal es la que toda la información relativa al objeto está encerrada en el más pequeño de sus detalles. De la misma manera podemos hablar hoy en día de un sujeto fractal que se difracta en multitud de egos miniaturizados todos parecidos los unos a los otros, se desmultiplica según un modelo embrionario como en un cultivo biológico, y satura su medio por escisiparidad hasta el infinito (p. 27).

Este proceso se observa en los diferentes campos que entran en contacto en la formación de la novela. Recientemente señalamos los quiebres temporales, los cuales ocurren por la utilización de cierto anacronismo, pero no es la única característica donde se presenta dicho rasgo, pues este también se encuentra en las características formales del texto, en la articulación del discurso por parte del narrador, en el narrador mismo y en cada uno de los procesos que son iluminados por él. Paralelamente, las conjeturas que tienen lugar en la figura del Marqués también responderían a un modelo fractal, pues la estatización temporal de episodios de su vida, la incapacidad de aceptar los cambios y procesos sociales, y por supuesto la excentricidad que lo caracteriza, no son otra cosa que un intento de sujeción temporal.

\section{FRACTALES, HISTORIAS, PERSPECTIVAS}

La historia del Marqués es desplegada por un narrador que posee un conocimiento medular de los pormenores de su vida, inclusive se permite licencias, pues la narración no es lineal y la utilización de raccontos, flashbacks y flashforwards es continuamente manejada, desconcertando al lector con eventos o situaciones, que muchas veces aún no ocurren, pero a partir de los cuales se pueden construir juicios performativos relacionados con la opinión que se expone en dicho espacio. Esto provoca una perspectiva amplia pero a la vez confusa, la narración y la historia se vuelven flexibles, a merced de la perspectiva y el orden elegidos por el narrador (curador), quien se sitúa en diferentes lugares, esgrime juicios de valor y, en otros casos, opina desde una cercanía que pareciese significarlo como un partícipe más de las circunstancias que le toca presenciar $^{8}$. Ejemplo de ello son los siguientes: "Nosotros, los de la tertulia del Club, sabíamos que la cocinera había llegado hasta su casa, pocas semanas antes" (2000, p. 74) o "Después nos contaron que el comerciante, a base de esfuerzo y de una austeridad catoniana, (...) había logrado amasar una fortuna considerable..." p. 20). Estas características plurales en la disposición del discurso nosotros, subrayan que quienes se encargan de traspasar la historia no son uno sino varios individuos. De alguna forma, la historia pública de esta ciudad comienza a circular en multitud de voces que refieren distintas perspectivas en relación a las historias del Marqués,

$8 \quad$ Rodríguez Isoba (1986) enfatiza esta cualidad del narrador de la novela que nos ocupa cuando señala que "desde los párrafos iniciales puede advertirse que el narrador asume un punto de vista colectivo. Cuando se hace presente utiliza siempre la primera persona del plural. Esa perspectiva es particularmente explícita en algunos momentos del relato" (1986, p. 225). 
pues al existir una multiplicidad de narradores se explicaría que no todos conocen de la misma forma los pormenores del relato. El registro memorial, entonces, comienza a ser comprendido como un ejercicio polifónico de múltiples, y en algunos casos, heterogéneos orígenes.

En esta zona del ejercicio novelesco es donde percibimos la característica fractal de la narración, donde las distintas voces se orquestan en pos de un entramado crítico supranovelesco. Como señalamos arriba, la focalización del Marqués se identifica con su condición de voyeur, que además transita y se desplaza por distintas mesetas sin mayor inconveniente. Es por esa condición que se le permite pasar desde el espacio burgués, al espacio popular, desde donde presencia los mecanismos de elevación estética de su amigo el escultor Demetrio Paredes, quien al introducirlo en un denominado "salón de los innovadores", le permite presenciar el espectáculo de "dos jóvenes poetisas drogadas, de ojos extraviados, delgadas y con una piel de apariencia lechosa, que se entrelazaban y se revolcaban desnudas sobre cojines de la misma felpa azul que cubría los asientos de piedra del vestíbulo" (2000, p. 111), imágenes que terminan por angustiar al Marqués haciéndolo perder la compostura. Esa respuesta se repetía en cada ocasión en que presenciaba algún hecho de importancia.

Por otra parte, la introducción del testimonio oral en la novela asegura otro afluente memorial que privilegia saberes moleculares parciales, mínimos, insuficientes, incompletos e inclusive contradictorios. El narrador se dirige a los lectores como si lo hiciera a un auditorio indeterminado de oyentes (Rodríguez, 1986), por lo tanto, el relato se reviste de oralidad y asume un estatus que complica y dificulta el registro narrativo, aun cuando, como dijimos arriba, se asegura una "versión" nueva sobre los hechos del pasado cuya dignidad amerita el resguardo al porvenir.

Nosotros, los que recordamos esta historia, pensamos a menudo en las materias inertes, los compromisos, las personas interpuestas, que conspiran para que nuestras palabras no lleguen a ustedes, dispuestos a escuchar el relato con ojos y oídos atentísimos, procurando obtener la indispensable diversión y la necesaria enseñanza que nos ofrece el pasado (2000, p. 111).

En dicha declaración percibimos los juegos textuales, en relación con los hechos ocurridos y a aqueIlos que no, y por supuesto reconocemos el juego de alternancia temporal. Pero además notamos el ingreso de la oralidad como principio constructivo del espacio dialógico, donde el lector asume un rol distinto al tradicional, ahora como un agente más de las circunstancias del relato. La condición fractal del espacio discursivo queda en evidencia a partir de la utilización de marcas textuales distintivas, las cuales a simple vista parecen ser alicientes de la historia, pero que en realidad, funcionan como marcas específicas de la construcción de la ficción, las cuales en una esfera enriquecen el texto, pero a su vez, dan cuenta de esa fragmentación, proceso hijo de las modalidades narrativas de la época contemporánea.

Los quiebres temporales provocados por el anacronismo tienden a exacerbar -al igual que la multiplicidad de narradores responde a la fragmentación y fractalidad-, la condición de una crítica que busca generar discursos de características duales: por una parte la construcción de una novela episódica y por otra la creación de una colección ${ }^{9}$ (galería o exposición), espacio museal con instantáneas acerca de la historia particular de la ciudad y del Marqués, actividades ambas propicias para la crítica sociopolítica, económica y cultural sobre aquella comunidad "imaginad"10. Aunque el relato se presenta como

$9 \quad$ La destacada historiadora del arte Aurora León (2010) describe cuatro valores culturales del coleccionismo en cuyas coordenadas percibimos el ejercicio curatorial del Marqués de Villa Rica. En primer lugar, afirma un mundo de preferencias ideológicas al definirse como defensor activo de la posesión única, no compartida; en segundo lugar, incide en la función ideológica de la cultura; en tercer lugar, tiene valor formativo-consolidante sobre el arte, la crítica y el gusto, y finalmente, impuso todos los valores ficticios para la valoración de la obra de arte.

10 Concepto acuñado por el destacado intelectual irlandés Benedict Anderson en Comunidades imaginadas. Reflexiones sobre el origen y la difusión del nacionalismo (1991). Con esta categoría pretende explicar la idea de nación, la cual entiende como una comunidad construida socialmente (imaginada) por un grupo de sujetos que se definen a sí mismos como parte del grupo, por lo cual "la nacionalidad es el valor más universalmente legítimo en la vida política de nuestro tiempo" (Anderson, 1991, p. 19) y debe ser comprendida como "artefacto cultural", emanado de una clase particular. En definitiva, entonces, nación es una comunidad política imaginada como inherentemente limitada y soberana. 
una construcción abarcadora y totalizante, es dispuesto desde un espacio simbólico mínimo, donde la ciudad es metonimia del país, es decir, Villa Rica parece sufrir todos los procesos constitutivos de la historia del país, cualquiera este sea. Villa Rica entonces, se vislumbra como una ciudad agraria, pero también como una urbe cosmopolita donde convergen artistas y bohemios con una aristocracia terrateniente. También parece tener problemas separatistas, vive el boom de una violencia política y dispone de parajes y lugares de un referente imaginario particular del sur de Chile, pero también responde a los patrones distribucionales de una ciudad capital. En definitiva, cifra todos los componentes de un relato nación. En todo ese contexto, se nos viene a la mente la pregunta ¿Cuál es el contexto de la ficción? Según Kundera (2005) "Son dos los contextos elementales en los que podemos situar la obra de arte: el de la historia de la propia nación (Ilamémoslo el pequeño contexto), o bien el de la historia supranacional de su arte (llamémoslo el gran contexto)" (p. 5).

Siguiendo el principio de fragmentación que se da en la escritura de $E l$ museo de cera, creemos que se articula en ambos contextos, pues otra característica fractal del relato es condensar la historia de un país, que a su vez es la de un continente. La novela a su vez responde a un estado supranacional y se vincula con distintas modalidades o recursos lingüísticos, todo cifrado en la figura de un latifundista venido a menos. Schulz-Cruz (1992) en el texto antes citado, señala:

El museo de cera retoma la preocupación histórica, observando el presente con los ojos de una reliquia del pasado. Esta es una novela muy diferente de las anteriores. La trama más sencilla y lineal, el sentido del humor, la parodia esperpéntica y la carnavalización de la historia de Chile demuestran la versatilidad de Edwards que, abandonando una escritura larga y pesada, reflexiona constantemente a través de una chispeante mascarada de aparentes sin sentidos, de cara al discurso oficial de la dictadura chilena. La historia se cuenta desde la literatura con desparpajo satirizante (p. 244).
Esta cualidad novelesca no podría ser posible sin el recurso de la fragmentación que permite exhibir e iluminar distintos espacios, tiempos, escenas históricas, etc. La fragmentación narrativa, por lo tanto, responderá a esa descripción que observa Jean Baudrillard (1990) cuando nos recuerda que una imagen no es la misma ni en el momento en que es captada, ni en su proceso de revelado, pues en su análisis y visualización ocurre una valoración. La escritura de Jorge Edwards, entonces, construye una valoración del proceso histórico y social de las nóveles naciones latinoamericanas, donde la fragmentación y la sátira abren un espacio crítico y sarcástico. Su tratamiento descreído respecto de los procesos sociales le permite apreciar el descalabro histórico social desde la comodidad de un espacio narrativo que inevitablemente adquirirá características de espacio museal que alberga, distribuye (curatoría), canoniza y pone en valor aquellas escenas que se incorporan dentro de sus límites de acuerdo a intereses puntuales. Por lo tanto, la fractalidad y el anacronismo de la obra posibilitan al autor desarrollar un discurso crítico molar, pues al cifrar distintos episodios históricos de una nación en un espacio literario reducido, el narrador puede dirigir e instalar ideas primordiales de su discurso, ya que en el espacio narrativo, al igual que en el espacio museal, permanecen solo los discursos ("los enunciados" dirá González Echevarría (2000) que parecen necesarios para sostener la memoria y resguardar un saber, donde se mantenga la paradoja bellamente descrita por Blanchot (1976), a propósito de alguna declaración de Valery: "Del mismo modo que no aceptaba con gusto la historia, no amaba los museos (...) donde veía soledades encerradas que participan de la naturaleza del templo y del salón, la escuela y el cementerio" (1999, p. 19)).

\section{MUSEO IMAGINARIO PERSONAL}

Repasemos brevemente la formulación del museo personal del protagonista. Lo primero que se nos señala es que "lo que el Marqués deseaba era que el Maestro reprodujera la figura de Gertrudis y la del profesor de piano en la exacta posición en que él los había sorprendido" (2000, p. 46), es decir, desde el origen mismo de la inquietud del coleccionista se encuentra la exhibición del ultraje sufrido por el 
Marqués, cifrado en la escena del adulterio. Más adelante se señala también:

Él exigía un trabajo perfecto, en que la ilusión de realidad fuera absoluta, de modo que si él mismo, distraído, abriera esa puerta, tuviera la sensación exacta, desconcertante, de que la escena se repetía, o de que era ése, más bien, el momento en que ocurría, y no el otro (2000, p. 47).

Estos hechos, que bien pudieran ser la primera negación del paso del tiempo por parte del Marqués, son más bien el primer síntoma de una obsesión somatizada por el aristócrata, desequilibrio que, en primer lugar, incide en su forma de relacionarse con el mundo, en segundo lugar, revela su incapacidad para aceptar situaciones y el paso del tiempo, y por último, muestra el extraño voyerismo que lo hace acercarse a absolutamente todas las manifestaciones humanas que tienen lugar en la ciudad. El mismo cuerpo del Marqués comienza a sufrir una transformación drástica al perder movilidad, primero en sus piernas, posteriormente en sus extremidades y finalmente en todo el cuerpo, es decir, deviene escultura ${ }^{11}$ :

Un día Gertrudis Ilamó al médico, porque el Marqués no tragaba ni una gota de sopa, todo se le escurría por las comisuras de los labios, y el doctor, después de confirmar que el pulso estaba extraviado, y de advertir, con asombro, que la luz de las pupilas se había extinguido, hasta el punto de que los ojos parecían cámaras de luto, dictamino que el Marqués había muerto hacía por lo menos tres semanas. "Si es que el deceso", dijo, "no se ha producido hace tres meses (2000, p. 181).

Las extrañas circunstancias de la muerte del Marqués enfatizan ese desplazamiento sufrido desde su carácter de espectador a objeto exhibido y, por lo

11 Cómo olvidar a Pigmalión, personaje mítico cuya historia conocemos en La metamorfosis de Ovidio. Escultor de oficio a la vez que rey de Chipre, nuestro personaje buscó incesantemente a una mujer con la cual casarse a condición de que fuera la más bella y perfecta de las féminas. En su búsqueda frustrada decidió dedicarse a la escultura en busca de una que pudiera expresar la belleza buscada a la vez que compensar la ausencia de una amada de carne y hueso. Al poco andar frente a la belleza de una de sus esculturas, se enamora de ella. tanto, contemplable. Su colección de obras significativas (figuras de cera), su museo imaginario (Malraux) lo constituyen escenas/relato que van siendo curatoriadas de tal manera que el personaje al devenir obra de arte se instala en el porvenir, lugar al que apunta toda colección. "Como el archivo, la novela atesora saber" (González Echevarría, 2000, p. 62) y en ese sentido la historia de Villa Rica y del Marqués exhiben -parafraseando a Castilla (2010)las evidencias materiales de todos los enunciados que componen el cuerpo de la cultura, sus indicios y sus marcas. La colección de escenas memoriales generada por el Marqués en principio nos recuerda la asociación museo-mausoleo de Adorno, recogida por Crimp ${ }^{12}$ (1995) a modo de epígrafe:

La palabra germana museal tiene tonalidades displicentes. Describe objetos frente a los cuales el observador ya no tiene una relación vital y que están en proceso de morir. Deben su preservación más a respeto histórico que a las necesidades del presente. Museo y mausoleo están conectados por más que asociación fonética. Los museos son los sepulcros familiares de las obras de arte (p. 44) ${ }^{13}$.

Esta decadencia percibida por el crítico sobre uno de los lugares de memoria (Nora, 2009) más reconocidos e importantes (el museo), cobra en la materialización narrativa del escritor chileno una dimensión positiva, o al menos, esperanzadora. Esas escenas reunidas en el museo de cera vienen a movilizar el pasado, a proponer una visión crítica de aquello seleccionado para el porvenir y por lo tanto, constitutivo de un presente que necesariamente se encuentra en proceso de selección y curatoría permanente.

Aumont (2001) y a propósito de la sentencia de Paul Valery "todo termina en la Sorbona", explica el fenómeno de domesticación del arte (de vanguardia

12 Crimp se sirve de los planteamientos de Foucault (2004) para evidenciar la transformación de las instituciones de poder y los nuevos discursos, en donde se plantea que el museo (junto al asilo, la clínica y la prisión) es una institución más de reclusión y por tanto, relacionada al poder. Desde su título "En las ruinas del museo" nos lleva a reflexionar sobre la decadencia del museo, no por la falta de arte sino por el descuido de los espacios dedicados a conservar y exponer las obras de arte.

13 Traducción propia. 
en el contexto de la reflexión del francés) cuando declara que este arte rebelde siempre resulta arte consagrado, tarde o temprano llega al museo que "parece haberse dotado de una capacidad de absorción verdaderamente digna de una ameba" (2001, p. 87). La actividad curatorial del terrateniente de Villa Rica y su trabajo con escenas memoriales, dejan de manifiesto precisamente ese interés por sacralizar ciertos enunciados (González Echevarría, 2000; Foucault, 2004) para resignificarlos ${ }^{14}$ e instalarlos en el porvenir, de modo que este lugar de memoria también adopta las características de un dispositivo o aparato estético (Déotte, 2012) que ejerce fuerza en el acto de seleccionar, reunir, separar y articular aquellos objetos (obras) de acuerdo con una intencionalidad política.

La fragmentación y el anacronismo, entonces, son los procedimientos a través de los cuales se van creando aquellas "ficciones del archivo" que González Echeverría (2000) define como

Narrativas que siguen buscando la clave de la cultura y la identidad latinoamericana, por lo que caen en la mediación suministrada por el discurso antropológico. Al igual que la etnografía actual, estos libros ya no aceptan el discurso del método institucional como algo dado, aceptando el carácter literario de todas las representaciones del Otro, incluso, o tal vez especialmente, si es otro Interno, como en el caso de la narrativa latinoamericana. Las ficciones del archivo no han renunciado a la promesa de la antropología, sino que sondean la propia antropología, convirtiéndose en una especie de etnografía de la antropología (p. 238).

En el discurso fragmentado de El museo de cera, Jorge Edwards, exhibe una conciencia crítica pues intenta abarcar todos los discursos con los cuales alguna vez ha entrado en contacto. De esta forma, introduce en pequeños fractales los discursos de su clase y también los de otros grupos sociales, por

14 Cerón (2001) además de comentar el texto de Douglas Crimp, plantea que "El museo no sólo involucra un proceso continuo de resignificación de los objetos, discursos e instituciones que conforman el campo del arte, sino que moviliza prácticas sociales, culturales y políticas que dan origen a procesos de inclusión y exclusión" (p. 145). ello la condición de voyeur del Marqués, subraya los alcances del procedimiento narrativo. SchulzCruz (1992) se refiere a la escritura del novelista chileno de la siguiente manera:

Edwards crea un espacio donde se desarroIlan "las famosas hazañas" de la burguesía chilena y de los que desertaron de ella. Es predominante el contraste entre pasado y presente, realidad y ficción, memoria personal y ajena. Los engranajes de autojustificación se sucederán a lo largo de la narración, mientras, en el trasfondo, el narrador pareciera sonreírse irónicamente (p. 244).

El espíritu crítico de Edwards, pero también su percepción hermenéutica de la historia, materializada en $\mathrm{El}$ museo de cera, donde espacio literario y espacio museal se conectan y convergen, nos permite penetrar en la naturaleza humana para darnos cuenta de que funcionamos como vehículos de transmisión -al porvenir- de las particularidades de nuestro espacio histórico que a veces parece ser más surrealista incluso que el espacio literario.

\section{CONCLUSIONES}

En el transcurso de estas páginas se ha logrado constatar que la preocupación e incorporación de referentes del mundo de las artes visuales en la novela de Edwards posibilita el cuestionamiento del relato histórico estático y sacralizado por el poder. Con la integración y desarrollo de esta modalidad textual, inevitablemente se configura un relato fragmentado en que la imposibilidad de identificación de un narrador específico, una perspectiva histórica definida y una estructura narrativa única, tributan a la consolidación de una serie de episodios que pareciera adscribirse a esa "necesaria enseñanza que nos ofrece el pasado" (112). La memoria, curatoriada por la novela, entonces, consagra y exhibe la decadencia de una clase social permanentemente en pugna con su "deber ser", idea enormemente sugestiva si entendemos que el principio generador del espacio museal es la deshonra del Marqués, cifrada en la estatua de cera que reproduce la infidelidad de que fuera objeto. 
El museo exhibido en la novela asume la categoría de lugar de memoria y de un dispositivo que ejerce fuerza en el acto de seleccionar, reunir, separar y montar aquellos objetos de acuerdo con una intencionalidad política. En la medida en que el Marqués se erige como curador y obra a la vez, sujeto crítico y criticado, el texto insiste en sostener que el museo de cera viene a movilizar el pasado, a proponer una visión desacralizadora de aquello seleccionado al porvenir y, por lo tanto, constitutivo de un presente que se encuentra en constante movimiento.

\section{REFERENCIAS BIBLIOGRÁFICAS}

Anderson, B. (1991). Comunidades imaginadas. Reflexiones sobre el origen y la difusión del nacionalismo. México: Fondo de Cultura Económica.

Ahumada, H. (1999). Escritoras del 50: Conciencia y memoria en el discurso literario chileno". Acta Literaria, 24 (1999), 5-15.

Aumont, J. (2001). La estética hoy. Madrid: Ediciones Cátedra.

Baudrillard, J. et al. (1990). Videoculturas de fin de siglo. Madrid: Cátedra.

Blanchot, M. (1976). La risa de los dioses. Madrid: Taurus.

Castilla, A. (2010). El museo como construcción política. El museo en escena. Política y cultura en América Latina. Buenos Aires: Paidós.

Cerón, J. (2001). El museo como representación de los conflictos sociales. Calle 14. Revista de investigación en el campo del arte. 7 (5), 142-151.

Crimp, D. (1995). On the museum`s ruins. Massachusetts: The MIT Press.

Déotte, J. (2012). ¿Qué es un aparato estético? Benjamín, Lyotard, Ranciere. Santiago: Metales Pesados.

Derrida, J. (2001). El cine y sus fantasmas (entrevista con Antoine de Baecque y Thierry Jousse). Cahiers du cinéma 556 (2001). Trad. de Fernando La Valle. Obtenido de http://redaprenderycambiar.com.ar/derrida/textos/ cine.htm.

Derrida, J. (1997). Mal de archivo. Una impresión freudiana. Valladolid: Trotta.
Edwards, J. (2000). El museo de cera. Barcelona: Tusquets.

Espinoza, M. (1958). Una generación. Atenea, 380-381, 66-67.

Fernández, C. (2004). El anacronismo: Formas y funciones. Actas do Colóquio Internacional Literatura e História. Porto: Facultade de Letras do Porto, vol. I, 247-259. Disponible en el sitio http://www.culturahistorica.es/ fernandez_prieto/literatura_e_historia.pdf.

Foucault, M. (2004). Vigilar y castigar. El nacimiento de la prisión. Argentina: Siglo XXI.

Giaconi, C. (24 de mayo, 1959). ¿Existe una Generación de 1950? Diario El Mercurio, Santiago de Chile.

Godoy, E. (1991). La generación del 50 en Chile: Historia de un movimiento literario (Narrativa). Santiago de Chile: Editorial La Noria.

Godoy, E. (1998). La Generación del 50 en Chile: razones y efectos de una polémica. América 21, 369-376.

Goic, C. (1960). La novela chilena actual. Tendencias y generaciones. Estudios de Lengua y Literatura como Humanidades. Santiago de Chile, Seminario de Humanidades, 37-45.

González Echevarría, R. (2000). Mito y archivo. Una teoría de la narrativa latinoamericana. México: Fondo de Cultura Económica.

Kundera, M. (2005). Literatura universal y literaturas nacionales. Claves de la razón práctica, 151, 4-9.

Lafourcade, E. (1959). Antología del nuevo cuento chileno. Santiago: Zig-Zag, 1954. Lafourcade, Enrique. Cuentos de la Generación del 50. Santiago: Editorial del Nuevo Extremo.

León, A. (2010). El museo. Teoría, praxis y utopía. Madrid: Cátedra.

Lopes, M. (2010). Compartir espacios, colgar ballenas y apoyar a las universidades. En: Castilla, A. (Comp.). El museo en escena. Política y cultura en América Latina (pp. 39-62). Buenos Aires: Paidós.

Maleuvre, D. (1999). Museum memories. History, technology, art. Stanford: Stanford University Press.

Malraux, H. (1956). El museo imaginario. Las voces del silencio. Buenos Aires: EMECÉ. 
Nieto, C. (2014). Historia de una actitud ante la forma: de la curaduría tradicional a la curaduría artística. Ebook disponible de forma gratuita en el sitio https:// play.google.com/store/books/details/Carolina_Nieto_ Ruiz_Historia_de_una_actitud_ante_I?id=EluPBAAAQ BAJ\&hl=es_419. Descargado el 25 de enero de 2016.

Nora, P. (2009). Pierre Nora en Les lieux de mémoire. Santiago: LOM.

Promis, J. (1993). La novela chilena del último siglo. Santiago: La Noria.

Rodríguez Isoba, M. T. (1986). Una visión paródica de la historia chilena reciente: El museo de cera, de Jorge Edwards. Anales de literatura hispanoamericana, 5, 219-230.

Schopf, F. (2004). Jorge Edwards y la nueva novela histórica en Hispanoamérica. Atenea, 490, 87-98.

Schulz-Cruz, B. (1992). Jorge Edwards: Las Novelas escritas bajo la dictadura. Actas Irvine, 92: [Actas de XI Congreso de la Asociación Internacional de Hispanistas] / Coord. por Juan Villegas, Vol. 4, 243-250.

Valery, P. (1999). Piezas sobre arte. Madrid: Visor. 